It seems clear that a small but significant number of people are simply ill-served by the existing format of mainstream mental health services. It may be (as I have heard in a European 'quality' forum) that such people are just peculiarly difficult. This seems unlikely, given a recent outcomes study we did of the most alienated and intractable of our referrals - people who live on the street and who have not been engaged by the sustained efforts of experienced street outreach teams. The intervention concerned was involuntary admission to hospital under a section of the Mental Health Act. $^{4}$ One year later, the majority were still engaged with the specialist mental health team and were still in accommodation. Here is an area ripe for research - the vital factors that enable such teams to engage effectively, and to maintain that engagement, with homeless people with psychotic disorders.

1 Craig TKJ, Timms PW. Out of the wards and onto the streets? Deinstitutionalization and homelessness in Britain. J Ment Health 1992; 1 265-75.

2 Winkler $\mathrm{P}$, Barrett $B$, McCrone $P$, Csémy $L$, Janous̆ková $M$, Höschl C. Deinstitutionalised patients, homelessness and imprisonment: systematic review. Br J Psychiatry 2016; 208: 421-8.

3 Salisbury TT, Thornicroft G. Deinstitutionalisation does not increase imprisonment or homelessness. Br J Psychiatry 2016; 208: 412-3.

4 Timms P, Perry J. Sectioning on the street - futility or utility? BJPsych Bull 2016; doi: 10.1192/pb.bp.115.052449 [Epub ahead of print].

Philip w. Timms, Consultant Psychiatrist, START Team, South London and Maudsley NHS Foundation Trust, London SE5 7UD. Email: philip.timms@slam.nhs.ukl; Tom K. J. Craig, Professor of Community Psychiatry, Institute of Psychiatry, London

doi: 10.1192/bjp.209.4.349a

Author's reply: I am grateful for the letters published by Mundt and Timms \& Craig as they raise several important points. Regarding the comments by Mundt, I agree that the mental health of prison populations is of serious concern and it deserves to be urgently addressed by developing and implementing cost-effective services.

I also agree that in countries which underwent deinstitutionalisation and were included in our review, ${ }^{1}$ excessively long-term hospital stays for psychiatric patients no longer commonly occur. After all, this was one of the main reasons that deinstitutionalisation was pursued. However, in the Czech Republic, for instance, $16 \%$ of in-patients with schizophrenia still stay in hospital for more than a year and hundreds remain in psychiatric hospitals for decades. ${ }^{2}$ Therefore, unfortunately, our review is not just of historical value but conveys an important message for current mental health systems in the majority of Central and Eastern European countries.

I acknowledge that neither our review nor ecological studies can (dis)prove whether new cohorts of patients who became imprisoned in the era after deinstitutionalisation would have also become imprisoned if the mental care systems were still hospital based. We have also admitted that the cohort of patients followed or traced in studies included in our review are not representative of all deinstitutionalized patients. ${ }^{1}$ However, what our study shows is that - contrary to some interpretations - there is scant evidence of adverse consequences for people who have been discharged from long-term institutional care. Our main point is that despite the importance of the data provided by ecological studies, these can be hardly helpful in showing whether there is a direct link between deinstitutionalisation and criminality. Moreover, it seems that ecological studies testing the Penrose hypothesis may have further important limitations, ${ }^{3}$ and as such are arguably of inherently limited value. Indeed, linkage studies could be theoretically much more relevant, but, regrettably, Mundt does not cite any of them.

Our review ${ }^{1}$ casts doubts on statements such as 'the general prison population has increased in all the countries, and this may be linked to the processes of deinstitutionalisation and reinstitutionalisation'4 or 'changes in capacities of psychiatric hospitals and prisons appear to be linked ${ }^{5}$ contained in the discussions and conclusions of some of the ecological studies. Our paper shows that at the individual level these statements have negligible empirical support, and they might be detrimental to mental health care reforms in countries of Central and Eastern Europe. ${ }^{1}$ As Salisbury \& Thornicroft ${ }^{6}$ argued, individual countries should focus on developing optimally balanced mental health care systems suitable to their setting.

There seems to be a clear consensus that substantial investment in community care is a condicio sine qua non of successful deinstitutionalization, which is why I suggest that cost-effective investments into mental health should replace the number of psychiatric beds as the 'hydraulic' in the updated Penrose hypothesis.

I would like to thank Timms \& Craig for complementing our review with their depiction of some of the pressing issues related to the current homelessness among people with mental health problems in South London. Their insights are extremely valuable and should be considered when pursuing mental health care reforms in the countries of Central and Eastern Europe. Unfortunately, although we know that homelessness associated with mental illness is a serious problem in the Czech Republic as well, this issue is extremely under-studied and only anecdotal evidence is available. I agree with the suggestion that more research is needed to understand what enables community teams to engage effectively with 'the most alienated and intractable' patients. This might be especially important when it comes to the period immediately following a discharge from in-patient psychiatric care, which is associated with other concerning phenomena, such as re-admissions ${ }^{2}$ and suicides. ${ }^{7}$

1 Winkler $\mathrm{P}$, Barrett $B$, McCrone $\mathrm{P}$, Csémy L, Janoušková $\mathrm{M}$, Höschl C. Deinstitutionalised patients, homelessness and imprisonment: systematic review. Br J Psychiatry 2016; 208: 421-8.

2 Winkler P, Mladá K, Krupchanka D, Agius M, Ray MK, Höschl C. Long-term hospitalizations for schizophrenia in the Czech Republic 1998-2012. Schizophr Res 2016; 175: 180-5.

3 Tsai AC, Venkataramani AS. Penrose Hypothesis not supported. JAMA Psychiatry; 72: 735-736.

4 Priebe S, Badesconyi A, Fioritti A, Hansson L, Kilian RT, Torres-Gonzales F, et al. Reinstitutionalisation in mental-health care: comparison of data on service provision from six European countries. Br Med J 2005; 330: 123-6.

5 Mundt AP, Chow WS, Arduino M, Barrionuevo H, Fritsch R, Girala N, et al. Psychiatric hospital beds and prison populations in South America since 1990: does the Penrose hypothesis apply? JAMA Psychiatry 2015; 72: 112-8.

6 Salisbury $\Pi$, Thornicroft $G$. Deinstitutionalisation does not increase imprisonment or homelessness. Br J Psychiatry 2016; 208: 412-3

7 Winkler P, Mladá K, Csémy L, Nechanská B, Höschl C. Suicides following inpatient psychiatric hospitalization: a nationwide case control study. J Affect Disord 2015; 184: 164-9.

Petr Winkler, Department of Social Psychiatry, National Institute of Mental Health, Topolová, Klecany, Czech Republic. Email: Petr.Winkler@nudz.cz

doi: 10.1192/bjp.209.4.350

\section{Trial of an intervention to reduce suicidal ideation and behaviour}

We take issue with the presentation of the findings of the study by Armitage et $a l,{ }^{1}$ on two counts. First, the title is misleading 